\title{
VOLUNTARIADO CORPORATIVO: EDUCAÇÃO FINANCEIRA
}

\author{
Leandro Bryk ${ }^{1}$
}

RESUMO: O objetivo do presente artigo é apresentar a implantação, por uma Seguradora, no Brasil, de um programa de voluntariado para melhoria de educação financeira, premiado internacionalmente pela UNESCO. Trata-se de uma iniciativa composta por treinamentos ministrados por voluntários da seguradora que visa a instruir jovens de baixa renda em gestão do dinheiro e aumentar sua percepção sobre os ganhos para vida pessoal oriundos de decisões financeiras conscientes. Programas de voluntariado corporativo e Educação Financeira são relevantes no contexto do país. Além disto, poucos estudos descrevem mecanismos bem-sucedidos sobre como implementar tais temáticas. O presente relato baseou-se emobservações participativas e entrevistas semiestruturadas com organizadores do programa. Como resultado, observou-se, em consonância com a literatura, que a participação de colaboradores em voluntariado contribui para a elevação do clima organizacional de uma empresa. Apesar disto, evidenciou-se que uma das problemáticas mais presentes em voluntariado em empresas é a falta de compromisso e perseverança potencialmente presentese que podem prejudicar os resultados da iniciativa social. Por fim, o estudo aponta resultados positivos na percepção dos alunos sobre o programa e indica práticas empresariais quepotencializam resultados em programas de voluntariado. $\mathrm{O}$ artigo, ao final, traz também recomendações para estudos futuros.

Palavras-chaves: Educação Financeira, Programas de Voluntariado, Responsabilidade Social Corporativa.

ABSTRACT: The purpose of this article is to present the implementation, by an insurance company in Brazil, of a voluntary program to improve financial education, internationally awarded by UNESCO. This initiative includes a training, given by volunteers from the insurance companythat aims to educate low-income youth in money management and increase their perception of the gains to personal life come from conscious financial decisions. Corporate volunteer programs and Financial Education are relevant in the context of the country. In addition, few studies describe successful mechanisms on how to implement such issues. This report was based on participant observation and semi-structured interviews with program organizers. Asa result, it was observed, consistent with the literature that the participation of employees in volunteering contributes to raising the organizational climate of a company. Nevertheless, it became clear that one of the present problems in volunteering in companies is the lack of commitment and perseverance that can potentially damage the results of the social initiative. Finally, the study shows positive results in the perception of the students about the program and indicates business practices that enhance results in volunteer programs. The article, in the end, also includes recommendations for future investigations.

Keywords: Financial Education, Volunteer Programs, Corporate Social Responsibility

${ }^{1}$ Bacharel em Ciências Econômicas (Universidade Nove de Julho, UNINOVE, Brasil), especialista em Controladoria Estratégica (Fundação Comercio Alvares Penteado, FECAP, Brasil), mestre em Administração com ênfase em Finanças (Fundação Comercio Alvares Penteado, FECAP, Brasil) 


\section{INTRODUÇÃO}

Com a preocupação cada vez maior com questões ambientais e sociais, os consumidores desenvolvem uma visão mais crítica acerca dos produtos e serviços ofertados pelas empresas, e por esta razão, as práticas de sustentabilidade ambiental e responsabilidade social corporativa têm-se demonstrado grandes diferenciais competitivos (Bertoncello e Júnior, 2007). Tais pressões fazem com que as empresas brasileiras invistam em ações de Responsabilidade Social, alinhando-as com suas estratégias de negócios (Coutinho, Macedo- Soares, 2006). Particularmente, as empresas têm estimulado práticas e trabalhos voluntários entre seus colaboradores, auxiliando projetos sociais e programas comunitários (Scheffer, 2001).

Neste contexto, Fernandes e Gremmelmaier (2014), em pesquisa sobre o nível de Educação Financeira no Brasil, constatam que falta preparo às novas gerações para tratar questões relativas à administração financeira pessoal, o que gera grande dificuldade em gerir suas finanças. Lührmann e Winter, (2012), em estudo semelhante realizado entre adolescentesde baixa renda na Alemanha, revelam que o treinamento sobre educação financeira, além de aumentar o interesse dos adolescentes por temas relacionados a finanças, desenvolve o consumo consciente. Tais fatos corroboram a relevância do tema a ser abordado no presente relato.

Apesar desta relevância, na literatura há poucos estudos que relatam casos de sucesso na implantação de projetos de voluntariado com enfoque em Educação Financeira. Visando preencher esta lacuna, o objetivo central do presente artigo técnico é apresentar a implantação, em nível nacional, de um programa de Educação Financeira para jovens, como parte do plano de Responsabilidade Social Corporativa de uma Seguradora Multinacional.

Esse programa foi desenvolvido na Alemanha, em 2010, e implantado em mais de 11 países, beneficiando mais de 120.000 crianças, através de treinamentos ministrados por funcionários voluntários, em salas de aula. Este programa foi reconhecido internacionalmente pela UNESCO como "Projeto da Década" no segmento de Educação para o Desenvolvimento Sustentável. Além disso, a iniciativa nacional relatada no presente artigo venceu também o Prêmio de Sustentabilidade da Câmara de Comércio França-Brasil. O objetivo deste programa liga-se à conscientização do uso do dinheiro e a melhoria das decisões financeiras diárias, fornecendo instrumentais para que os jovens se tornem cidadãos financeiramente responsáveis. Contudo, a implantação de programas de voluntariado é desafiadora e carece de estudos que caracterizem suas melhores práticas. Desta forma, a pergunta que norteia esse trabalho é: Quais são as práticas bem-sucedidas, os desafios enfrentados e os benefícios auferidos em cada etapa de um programa de voluntariado em Educação Financeira?

A justificativa para o presente relato baseia-se em retratar as práticas necessárias parao sucesso na implantação de um programa como o descrito, que poderão contribuir para futuras ações desta natureza. Segundo uma pesquisa realizada pelo Instituto Gallup, divulgadapelo site da $\mathrm{BBC}$, em uma pesquisa mundial sobre o nível de analfabetismo realizada em2014, com 148 mil pessoas, dois em cada três adultos podem ser considerados analfabetos financeiros e o Brasil ocupa o $68^{\circ}$ lugar em ranking de conhecimentos financeiros. 
Nos itens a seguir, será sintetizada a importância da alfabetização financeira na conjuntura nacional, o contexto da situação problema antes da implantação da iniciativa, e posteriormente a descrição das etapas na implantação da iniciativa, bem como as situações vividas e finalmente os resultados auferidos. Por se tratar de um relato técnico científico de cunho descritivo-qualitativo, foi adotada como metodologia a condução de entrevistas semiestruturadas com os organizadores do programa. Além disto, o projeto teve a participaçãode um dos autores em uma das etapas. Em adição, o presente material foi discutido em sala deaula no contexto de um programa de Mestrado Profissional em Administração.

\section{Referencial Teórico}

Educação em si, tornou-se um ativo precioso em toda a sociedade contemporânea. Sem uma educação efetiva a sociedade encontra dificuldades em evoluir, principalmente num ambiente globalizado. Segundo Savoia, Saito e Santana (2007), educação financeira é um processo de aquisição de conhecimentos que cada indivíduo adquire com a finalidade de gerenciar melhor suas finanças pessoais. Pires (2007, p.13) define que "Finanças pessoais tempor objetivo de estudo e análise das condições de financiamento das aquisições de bens e serviços necessários à satisfação das necessidades e desejos individuais".

Segundo Holzmann e Miralles (2005), países anglo-saxônicos, como Austrália, Canadá, Nova Zelândia, EUA e Reino Unido estão mais avançados neste contexto de educação financeira. No contexto dos EUA, recentes crises econômicas têm demonstrado ser importante que os indivíduos sejam bem informados para poder tomar decisões financeiras. Os produtos financeiros têm se tornado muito mais complexos, elevando então a importância da educação financeira. Não é surpresa a classe política ter reforçado a necessidade deste tema(Batty, Collins e Odders-White, 2015). De acordo com Bernheim, Garrett e Maki (2001),entre o período de 1957 a 1985, o processo de educação financeira foi instituído em lei, em 29dos 50 estados e um distrito existentes, como mandatório nas escolas secundárias. O Brasil tem enfrentado diversos desafios econômicos, tendo havido, no período de 1942 a 1994, oito mudanças de moeda. Neste contexto a educação financeira, geralmente negligenciada, é algo relativamente novo, sendo incomum as famílias discutirem planejamento financeiro, principalmente com a participação dos filhos infantes e adolescentes (Souza, 2012).

Segundo estudos, o ato de economizar deve ser desenvolvido e estimulado desde cedo (Pereira, 2009). Crianças recebem mesadas, porém não são devidamente instruídas a pouparao menos parte dos valores recebidos, mas geralmente habituamse a consumir, pois sabem que no próximo mês terão suas mesadas novamente. Portanto, cabe-se uma correção neste processo: as crianças, ao receberem suas mesadas, devem ser educadas e estimuladas a pouparao menos parte do valor recebido. (Pelicioli, 2011).

O sistema educacional brasileiro deixava muito a desejar no que tange à educação financeira. $\mathrm{O}$ indivíduo sai do ensino médio sem uma educação formal a respeito da melhor forma de gerenciar seus ativos e passivos. Em complemento, quando ingressam nas universidades este tema segue com baixo grau de importância 
(Lima e Detoni, 2009). Pelicioli(2011, p.64) conclui que: [ ]

"sem estabelecer diferenças entre escolas públicas e privadas. Ambas parecem alheias aos Parâmetros Curriculares Nacionais, inclusive no que tange à interdisciplinaridade, pois não seria exclusivamente da área de Matemática a função de conectar nexos financeiros com conteúdos de aula. As áreas da História, Língua Portuguesa e Sociologia poderiam estabelecer conexões com a área financeira."

Recentemente o Brasil passou a dar a devida importância para este tema, através da Presidência da República, que instituiu o decreto n. 7.397 de 22 de dezembro de 2010, criandoa "Estratégia Nacional de Educação Financeira - ENEF , com a finalidade de promover a educação financeira e previdenciária e contribuir para o fortalecimento da cidadania, a eficiência e solidez do sistema financeiro nacional e a tomada de decisões de consumo conscientes por parte dos consumidores".

Além das iniciativas governamentais, está cada vez mais forte a prática de voluntariado. Lamóglia (2003, p.5) define assim o voluntariado: "além de visar melhorias de cunho social, constitui uma grande oportunidade para que os integrantes de uma equipe desenvolvam e exercitem algumas habilidades, criatividade, liderança e comunicação interpessoal". Garcia (2006, p.178) define que a prática das empresas vai além das fronteiras econômicas e legais, estas possuem também responsabilidades éticas, morais e sociais; estas ações devem estar integradas em uma agenda única, combinando as ações governamentais e empresariais.

\section{Método da Produção Técnica}

Esse trabalho adota uma abordagem descritivo-qualitativa dos processos desenvolvidos para a implantação da iniciativa, e em sua fase inicial foi realizado o levantamento de dados primários junto a documentos disponibilizados pela empresa responsável pelo programa, pois as fontes documentais possuem condições de proporcionar quantidade e qualidade suficiente para realizar uma análise mais aprofundada.

$\mathrm{Na}$ sequência houve uma rodada de entrevistas semiestruturadas com os responsáveis técnicos da empresa, com coordenadores pedagógicos e outros participantes do programa, a fim de não somente retratar as experiências técnicas na implantação, mas também captar as impressões, nuances e percepções dos entrevistados acerca do programa. Gil (2008, p. 109), destaca que: [...]

\footnotetext{
"Muitos autores consideram a entrevista como a técnica por excelência na investigação social, atribuindo-lhe valor semelhante ao tubo de ensaio na Química e ao microscópio na Microbiologia."
}

Este trabalho contou ainda com a participação ativa de um dos autores em uma das fases do programa, o que constituiu uma vantagem adicional para a sua elaboração, pois possibilitou corroborar o interesse do público alvo pela iniciativa, a integridade do programa, bem como a qualidade dos treinamentos ministrados. Em adição, o presente material foi discutido em sala de aula no contexto de um programa de Mestrado Profissional em Administração. 


\section{Contexto Investigado e Situação-Problema}

\subsection{Educação financeira no Brasil.}

Conforme é demonstrado adiante, através de pesquisas sobre inadimplência e endividamento, a falta de planejamento financeiro não tem gerado os melhores resultados na vida das famílias brasileiras. $\mathrm{O}$ crescimento da economia familiar, que deveria ser baseado empoupança, é baseado em crédito (BCB, 2013, p.15), apesar das altas taxas de juros.

Crianças são ensinadas, desde muito cedo, sobre a atratividade do consumo. Mais tarde, começando a ter sua própria renda, os jovens são estimulados a ter conta corrente, normalmente com limite de cheque especial e cartão de crédito (Lins e Pereira, 2011), quandodeveriam ser estimulados a poupar, com plano de investimento de curto, médio e longo prazos(Amadeu, 2009). A Tabela 1 mostra os índices de inadimplência no cartão de crédito rotativo. Constata-se, por exemplo, no mês de dezembro de 2015 , que $40,4 \%$ do valor das faturas não foram totalmente pagas no vencimento, mas refinanciadas na modalidade de crédito rotativo.

\begin{tabular}{|c|l|}
\hline \multicolumn{2}{|c|}{ Inadimplência Cartão de Crédito Rotativo - Pessoas Físicas (\%) } \\
\hline Dez/11 & 39,0 \\
\hline Dez/12 & 37,8 \\
\hline Dez/13 & 36,0 \\
\hline Dez/14 & 37,1 \\
\hline Dez/15 & 40,4 \\
\hline \multicolumn{2}{|c|}{ Tabela 1: Inadimplência no cartão de crédito - Fonte: BCB Séries Temporais }
\end{tabular}

A Tabela 2 mostra a taxa de inadimplência, em todas as modalidades de crédito para pessoa física, por faixa etária. Percebe-se neste levantamento de 2014 que ela é mais alta na faixa de tomadores entre 18 e 40 anos e chega a praticamente $30 \%$ na faixa de 26 a 30 anos.

\begin{tabular}{|c|l|}
\hline \multicolumn{2}{|c|}{ Taxa de Inadimplência por Faixa Etária (\%) em dezembro de 2014} \\
\hline $18-25$ & 28,1 \\
\hline $26-30$ & 29,9 \\
\hline $31-35$ & 29,3 \\
\hline $36-40$ & 28,2 \\
\hline $41-50$ & 24,4 \\
\hline $51-70$ & 17,1 \\
\hline Acima de 70 & 10,3 \\
\hline
\end{tabular}

Tabela 2: Inadimplência por faixa etária - Fonte: Serasa Experian

A falta de conhecimentos básicos sobre taxas de juros, mercado de crédito e inflação, bem como a falta de disciplina financeira, podem produzir decisões com resultados de baixa qualidade. Tais dados vão ao encontro do observado por Saito 
(2007) o qual diz que decisões financeiras devem ser planejadas levando em conta a capacidade futura de pagamento, bem como a eventual perda desta capacidade, o que exige a formação de reservas. Para corrigir estes resultados, as famílias, por vezes, tomam a decisão de usar linhas de crédito de alto custo como o cheque especial e o financiamento rotativo no cartão de crédito que, como demonstra-se na Figura 1, têm as maiores taxas do mercado em comparação com as taxas médias de empréstimos para pessoas físicas e, também, com a taxa SELIC.

Depois da implementação de políticas de rearranjo da economia brasileira, como o Plano Real, e do crescimento econômico mundial, era esperado um aumento de consumo por parte das famílias. A facilidade na obtenção de crédito, fomentada pelo governo, especialmente no período de 2005 a 2012, fez com que as famílias brasileiras se endividassemem níveis muito acima do recomendado, gerando aumento de inadimplência nos anos posteriores (Tabela 3).

\begin{tabular}{|l|l|l|l|}
\hline & $\begin{array}{c}\text { Média do Endividamento Mensal das } \\
\text { Famílias com o Sistema Financeiro } \\
\text { Nacional, em relação à renda acumulada } \\
\text { nos últimos 12meses (\%) }\end{array}$ & $\begin{array}{c}\text { Média do Saldo Mensal } \\
\text { das Famílias na Carteira } \\
\text { de Cheque Especial } \\
\text { (R\$ Milhões) }\end{array}$ & $\begin{array}{c}\text { Média de Concessões Mensais } \\
\text { de Crédito na Carteira de } \\
\text { Cartões de Crédito PF - } \\
\text { (R\$ Milhões) }\end{array}$ \\
\hline 2011 & 41,06 & 21.787 & 56.664 \\
\hline 2012 & 43,06 & 23.646 & 61.127 \\
\hline 2013 & 44,73 & 24.137 & 72.967 \\
\hline 2014 & 45,67 & 26.261 & 84.408 \\
\hline 2015 & 45,86 & 26.957 & 87.557 \\
\hline
\end{tabular}

Endividamento e inadimplência interferem na produtividade dos indivíduos no trabalho, bem como podem causar transtornos ou dificuldades na busca de recolocação, poisas empresas resistem em contratar indivíduos com problemas cadastrais. Não há poucasevidências de que a educação financeira aumente à medida que aumenta o número de anos de estudo (correlação positiva). Programas como este, alvo deste trabalho, podem indicar que o aprendizado das boas práticas financeiras na adolescência dará boas ferramentas para que, quem dele participar, tome ao longo de sua vida as melhores decisões financeiras.

Possivelmente os melhores motivos para o aprendizado financeiro na adolescência estejam relacionados ao fato de facilidades no aprendizado ou, ainda, pelo fato de que,começando-se cedo, o resultado é muito melhor devido ao efeito das taxas compostas dejuros.

\subsection{Educação financeira no currículo das escolas brasileiras.}

Mesmo sem a percepção de toda a sociedade sobre os possíveis efeitos da falta de Educação Financeira, demonstrados por pesquisas sobre endividamento e inadimplência, parteda sociedade e, principalmente, o MEC (Ministério da Educação) estão atentos à necessidade de inserção da temática Educação Financeira na educação básica. Segundo informações no site do MEC, em matéria de 25 de fevereiro de 2016, cujo título é "MEC Apoia Inserção da Temática Educação Financeira no Currículo da Educação Básica", o Ministério, depois de algumas experiências-piloto bem- 
sucedidas, trabalha para que a Educação Financeira passe a compor a Base Nacional Comum Curricular (BNCC).

Como ilustração das ações tomadas neste programa, pode-se citar um programa-piloto realizado entre os anos de 2010 e 2012, envolvendo 891 escolas públicas de ensino médio de algumas unidades da federação (UF) que, segundo o MEC, teve resultados muito satisfatórios e significativos. Em 2015, escolas públicas da rede municipal de ensino de Joinville (SC) e Manaus (AM) deram sequência à experiência. Os resultados, na análise de dois grupos: o de tratamento, que recebe o treinamento, e o de controle, que não recebe, são comparados entresi a fim de medir a eficácia do treinamento, o que comprovou a mudanças das atitudes nas decisões financeiras dos jovens. O programa treinou 1.200 professores e atingiu 27.000alunos com idades entre 14 e 17 anos. A Tabela 4 mostra a distribuição de escolas e de alunos por unidades federativas (UF) e por grupos de tratamento e controle.

\begin{tabular}{|l|l|l|l|l|l|l|}
\hline \multirow{2}{*}{ UF } & \multicolumn{2}{|l|}{ Escolas } & Alunos & \multicolumn{2}{l|}{} \\
\cline { 2 - 7 } & $\begin{array}{l}\text { Grupo de } \\
\text { Controle }\end{array}$ & $\begin{array}{l}\text { Grupo de } \\
\text { Tratamento }\end{array}$ & $\begin{array}{l}\text { Controle }+ \\
\text { Tratamento }\end{array}$ & $\begin{array}{l}\text { Grupo de } \\
\text { Controle }\end{array}$ & $\begin{array}{l}\text { Grupo de } \\
\text { Tratamento }\end{array}$ & $\begin{array}{l}\text { Controle + } \\
\text { Tratamento }\end{array}$ \\
\hline Ceará & 60 & 62 & $\mathbf{1 2 2}$ & 1.959 & 2.012 & $\mathbf{3 . 9 7 1}$ \\
\hline Distrito Federal & 32 & 32 & $\mathbf{6 4}$ & 1.112 & 1.105 & $\mathbf{2 . 2 1 7}$ \\
\hline Minas Gerais & 15 & 14 & $\mathbf{2 9}$ & 371 & 360 & $\mathbf{7 3 1}$ \\
\hline Rio de Janeiro & 136 & 134 & $\mathbf{2 7 0}$ & 3.752 & 3.513 & $\mathbf{7 . 2 6 5}$ \\
\hline São Paulo & 192 & 180 & $\mathbf{3 7 2}$ & 6.037 & 5.741 & $\mathbf{1 1 . 7 7 8}$ \\
\hline Tocantins & 17 & 17 & $\mathbf{3 4}$ & 514 & 505 & $\mathbf{1 . 0 1 9}$ \\
\hline Total & $\mathbf{4 5 2}$ & $\mathbf{4 3 9}$ & $\mathbf{8 9 1}$ & $\mathbf{1 3 . 7 4 5}$ & $\mathbf{1 3 . 2 3 6}$ & $\mathbf{2 6 . 9 8 1}$ \\
\hline
\end{tabular}

Um dos aspectos interessantes desse programa piloto foi a forma que o tema de Educação Financeira foi inserido na grade curricular: de forma transversal no currículo escolar dos jovens, utilizando 72 situações didáticas em outras disciplinas como matemática, português, ciências entre outras disciplinas. Segundo Campos (2012), essa nova modalidadede inserção proporciona melhores resultados, por fazer com que o aluno compreenda que Educação Financeira não está relacionada intrinsecamente apenas com a Matemática. Ao se determinar a inclusão da Educação Financeira nas grades curriculares do ensino médio, visa- se atingir os jovens que estão entrando no mercado de trabalho, procurando desenvolver sua proficiência financeira. Vários autores destacam a importância na adoção da Educação Financeira na grade curricular do ensino médio:

"Na verdade, sou inconformado com o fato de não existir obrigatoriamente a disciplina de Educação Financeira no ensino médio das escolas brasileiras. Afinal, a falta de poupança é a origem de muitos problemas nacionais, assim como a falta de crédito e os juros elevados" (Cerbasi, 2004, p. 51).

\section{Análise Da Intervenção Adotada}

A partir deste ponto, o relato apresenta as práticas adotadas para a implantação do programa de Educação Financeira orientado para jovens do Ensino Médio como 
parte do plano de responsabilidade social da Seguradora. O programa, conforme demonstrado a seguir,baseou-se nas implantações em outros países e para a adoção no Brasil.

A proposta do programa foi desenvolvida na Alemanha em 2010 como uma iniciativa, sem fins lucrativos, tendo apoio de 60 empresas dos mais diversos segmentos, tendo tambéma participação da matriz da Seguradora. Este programa foi concebido com o intuito deproporcionar instrução aos jovens, para que administrem de forma inteligente suas finanças pessoais e para que adotem as questões financeiras como principais valores, além de ser uma iniciativa sem fins lucrativos, demonstrar transparência em suas ações, e disseminar valores sociais como voluntariado.

Atualmente o programa está implantado em 11 países, atingindo mais de 120 mil jovens e crianças, foi premiado pela Unesco - agência da ONU voltada para Educação, Ciência e Cultura - como Projeto da Década dedicado ao tema "Educação para o Desenvolvimento Sustentável" e a experiência no Brasil, em 2014, venceu o Prêmio deSustentabilidade LIF, da Câmara de Comércio França-Brasil (CCFB), na categoria Público Interno ao promover o engajamento dos colaboradores à causa. Tudo teve início quando o diretor da área de Relações Institucionais da subsidiária brasileira, em visita a Alemanha, em 2013 recebeu a proposta de iniciar o programa no Brasil. Nas palavras do diretor, "É essencial para a sociedade, como um todo, que crianças e adolescentes tenham conhecimentos financeiros, e nós, como empresa e voluntários, desenvolvemos um importante papel em auxiliá-los nesta jornada. É muito gratificante".

A implantação do programa teve como principais estágios: (i) Definição da estrutura para implantação do programa, (ii) Estabelecimento de parcerias com as escolas que seriam escolhidas, (iii) Propagação e divulgação da iniciativa entre os colaboradores da Seguradora visando o recrutamento de voluntários, (iv) Adequação dos materiais didáticos internacionais para a realidade nacional, (v) Aplicação das palestras, (vi) Avaliação dos resultados e (vii) Expansão do Programa. O tempo de implantação do programa foi de aproximadamente oito meses, conforme demonstrado a seguir na figura 2 , e vem sendo aperfeiçoado a cada edição anual, buscando atingir um maior público.

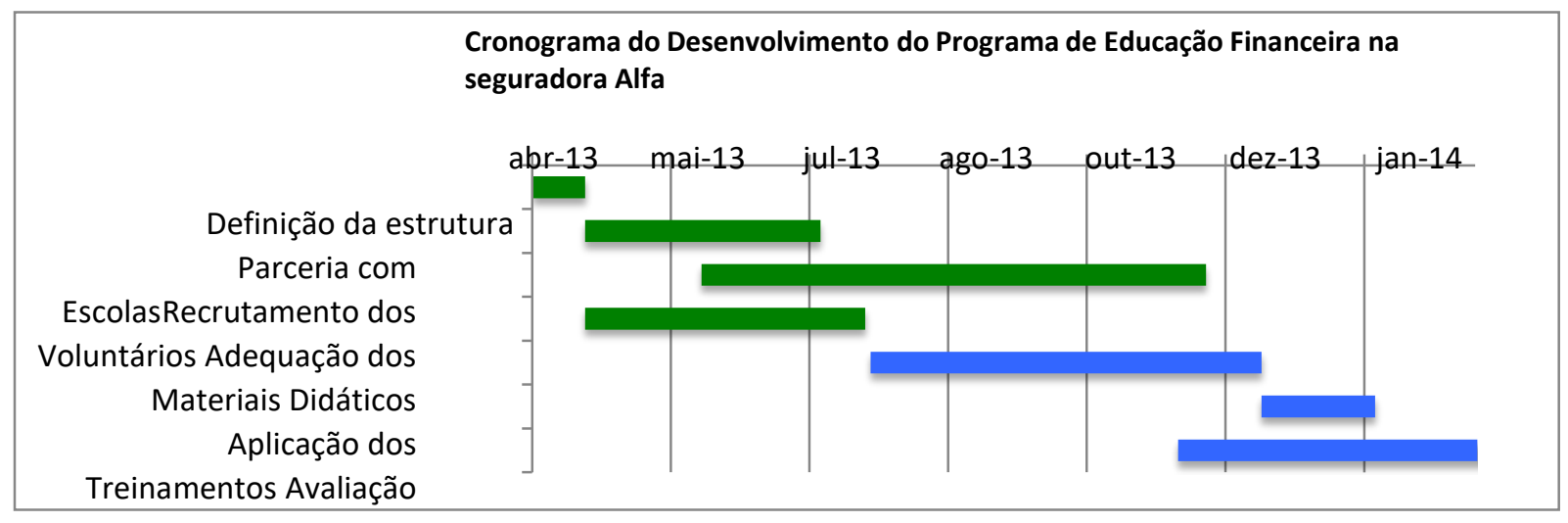

Figura 2: Elaborada pelos autores

\subsection{Fases da implementação do programa no Brasil:}


A seguir serão descritas as etapas da implantação:

Definição da estrutura a ser adotada. O tempo estimado de implantação do projeto foi de oito meses, sendo designados inicialmente dois funcionários da área de Sustentabilidade da empresa, em tempo integral para a implantação e desenvolvimento do projeto, que foram treinados na Alemanha para obter os conhecimentos necessários com o projeto original.Segundo Harry e Schroeder (2000), é fator crítico de sucesso para a implantação de umprojeto não somente a composição da equipe por pessoas com perfis adequados, mas o seu treinamento. Optou-se em não fragmentar a implantação do projeto entre as áreas envolvidas, mas formar uma equipe que fosse totalmente responsável por ele, tornando a sua implantação mais efetiva.

Estabelecimento de parceria com as escolas para implantação da iniciativa. O escopo inicial adotado internacionalmente definiu como público-alvo jovens aprendizes de 16 a 18 anos. A escolha se justifica pela fase de ingresso no mercado de trabalho, onde as dúvidas sobre aspectos financeiros cotidianos aumentam. Uma coordenadora do núcleo de formação profissional relata: "Este assunto é muito importante para estes jovens que estão iniciando suas carreiras profissionais. Ao receberem seus salários, eles terão mais consciência sobreos gastos. O planejamento financeiro que eles farão está inteiramente ligado aos seus projetos de vida".

$\mathrm{Na}$ sequência, foi efetuado o mapeamento das escolas que receberiam a proposta do programa de Educação financeira. Foi dada preferência para escolas próximas à sede da

matriz da empresa em São Paulo/SP com o intuito de facilitar a logística de deslocamento dos colaboradores-voluntários. Através de reuniões com diretores e coordenadores pedagógicos das escolas, foi apresentada a proposta do projeto, bem como o detalhamento do material didático, metodologia e a transparência do programa para não haver dúvidas sobre seu caráter sem fins lucrativos. Algumas escolas demonstraram receio e certa resistência com relação ao projeto por terem vivenciado experiências negativas ao participar de iniciativas que se intitulavam com cunho social. "Já tivemos ações parecidas no passado, e tivemos um histórico bem negativo, prometiam respeitar certos princípios, porém na prática, vieram com a ideia em oferecer produtos e serviços aos alunos" - relata uma coordenadora pedagógica de uma das escolas participantes do projeto. Para Coutinho, Macedo-Soares e Silva, (2006) a gestão deve assegurar que tais produtos, resultados e impactos sejam coerentes com a concepção e os fins do projeto.

Uma das preocupações do projeto foi justamente não realizar qualquer tipo de marketing, e os voluntários no treinamento recebem orientações expressas sobre esse ponto para apenas identificar-se como sendo meros funcionários da Seguradora. Cuidados em não utilizar a logomarca da empresa nos materiais didáticos, entre outros, foram tomados para demonstrar que se tratava de uma ação séria e transparente e reconhecida internacionalmente. Segundo Tavares (2013), a educação financeira deve ser aplicada de forma justa, e não tendenciosa, baseada em instruções e informações apropriadas, sem a influência de interesses particulares. Questionado sobre a posição da Seguradora em não utilizar o projeto como ferramenta de Marketing Social, o organizador ressalta que essa iniciativa não é exclusiva da Seguradora, pois tem a 
participação de outras 60 empresas participantes em todo mundo. Conforme Gernhardt (2002), indica que a prática de marketing social ao ser utilizada de formainadequada pode trazer sérios prejuízos à imagem da empresa, e segundo Higuchi e Vieira (2012), o marketing social, ao fornecer subsídios para influenciar a opinião pública sobre questões sociais, pode ser manipulativo e potencialmente antiético.

Divulgação da iniciativa entre os colaboradores visando a obtenção de voluntários. Um dos maiores desafios encontrados na implantação da iniciativa foi despertar o engajamento dos colaboradores na causa do projeto. Para propagar a ideia do voluntariado, foram realizadas campanhas internas de comunicação com a participação de diretores e do presidente daempresa disseminando os valores sociais da iniciativa. "Uma das preocupações, foi demonstrar que todos poderiam estar engajados na causa e, como exemplo, o presidente ministrou uma das palestras juntamente com um estagiário", ressalta um dos organizadores. Segundo Maximiano e Trad (2009), "o sucesso na implantação não acontece sem umaliderança ativa com objetivos claramente traçados e comunicados aos funcionários. "

Em linhas gerais, as motivações dos colaboradores em participar do projeto foram as mais diversas possíveis: religiosas, senso de cidadania, desenvolvimento de competências e incentivo da empresa em fazer um trabalho social. Um dos voluntários afirma que desejava encontrar uma forma de contribuir com a melhoria da sociedade, e encontrou a oportunidade no projeto: "Identifiquei-me com a causa, e com o incentivo da empresa, ficou mais fácil". Mascarenhas, Zambaldi e Varella (2001), reforçam que o voluntariado traz mútuas vantagens, gerando benefícios para todas as partes e relacionam os benefícios com as motivações dos participantes de programas de voluntariado, conforme tabela 5:

\begin{tabular}{|l|l|}
\hline Categoria & Pesquisa e teoria \\
\hline Motivações altruístas & $\begin{array}{l}\text { Pesquisas apontam para o “ajudar", ou "fazer o bem” como a razão mais } \\
\text { alegada para o voluntariado. }\end{array}$ \\
\hline Categoria & Pesquisa e teoria \\
\hline Motivações ideológicas & $\begin{array}{l}\text { Voluntários alegam causas específicas ou ideologias para o engajamento } \\
\text { em atos voluntários. As pessoas envolvem-se em atos voluntários para } \\
\text { satisfazer necessidades do ego, como, por exemplo, a aprovação social. }\end{array}$ \\
\hline Motivações materiais & $\begin{array}{l}\text { Incluem benefícios para a própria pessoa ou família. Segundo muitos } \\
\text { teóricos, as pessoas são voluntárias prevendo benefícios materiais }\end{array}$ \\
\hline Motivações de status & $\begin{array}{l}\text { O desejo de adquirir conhecimento profissional, contatos e } \\
\text { reconhecimento é mais acentuado em pessoas em idade de trabalho e em } \\
\text { estudantes. }\end{array}$ \\
\hline Motivações de lazer & $\begin{array}{l}\text { Encontrar pessoas e fazer amizades são motivos alegados por muitos } \\
\text { voluntários. }\end{array}$ \\
\hline Motivações de crescimento pessoal & $\begin{array}{l}\text { O voluntariado é uma forma de lazer para muitas pessoas. Muitos } \\
\text { voluntários respondem que se engajam nestas atividades por terem } \\
\text { "tempo livre". }\end{array}$ \\
\hline \hline
\end{tabular}

Tabela 5 - Fonte: Adaptado de Mascarenhas, Zambaldi e Varela (2001)

Os voluntários passam por um treinamento de três horas, sobre a metodologia 
pedagógica adotada, bem como a estrutura do material didático disponibilizado, além de assinar um termo de boa conduta nos moldes da lei do voluntariado (Lei 9.608/98), estando aptos a ministrar as palestras com 90 minutos de duração. Houve aderência à causa, sendo queem um ano após a sua implantação, 205 colaboradores receberam treinamento, tornando-se aptos para ministrar as palestras em polos como Grande São Paulo, Rio de Janeiro e Campinas, representando 11,91\% dos colaboradores da empresa. " $O$ alto índice do voluntariado serve também para demonstrar a qualidade do ambiente interno da Companhia" relata um dos organizadores. Ashley e MacedoSoares (2002) relata que, em pesquisa realizada pela IBM, 75\% dos entrevistados afirmaram que uma empresa com plano de trabalho voltado ao voluntariado atrai e retém talentos.

No entanto, apenas 48 voluntários ministraram mais do que 4 palestras por ciclo. Esse número se justifica por diversos motivos, entre eles, a conciliação das agendas do ambiente corporativo com o das palestras, por motivos pessoais dos voluntários e até mesmo pela resistência de alguns gestores, mesmo o programa sendo apoiado pelo alto escalão da empresa. Para que o engajamento à causa seja consistente, ações internas de estímulos são tomadas regularmente. "Sempre nos dias do voluntariado, 05/12 (internacional) e 28/08 (no Brasil), preparamos ações internas que têm por objetivo lembrar que podemos fazer algo a mais pela sociedade." (Grifo nosso)

Adequação da metodologia e materiais didáticos internacionais para a realidade nacional. Os materiais de ensino são disponibilizados gratuitamente e foram desenvolvidos em parcerias com editoras de livros escolares alemães, buscando refletir os mais recentes padrões e métodos científicos e educacionais.

Foram desenvolvidos vários módulos de aprendizagem em assuntos inerentes a Educação Financeira, que são apresentados por voluntários devidamente treinados, e posteriormente são disponibilizados materiais extras, propiciando a consolidação dos assuntosabordados que podem ser aplicados em sala de aula ou serem dados como tarefa de casa. Comisso, procura-se aumentar o incentivo da instituição de ensino a aprofundar o tema levado pelovoluntário. Para adequar esse material à realidade do Brasil, foram contratadas empresas especializadas em educação para realizar a tradução e tropicalização do material didático, além de optar-se inicialmente na implantação de dois módulos a fim de verificar a receptividade do material pelo público-alvo. Foram escolhidos os módulos "Planejamento" e "Compras":

Módulo Planejamento: tendo como objetivo principal instigar a prudência dos jovens ecrianças com relação a suas finanças, busca, através de conceitos simples, planejar o controle de suas receitas e despesas para alcançar seus objetivos futuros. Uma das formas de aprendizagem é a dramatização de situações cotidianas que ajudam os jovens a identificar a importância do planejamento. Os alunos são convidados, ao longo da palestra, a dividirem experiências sobre o assunto e, com apoio de planilhas, realizam trabalhos em pequenos grupos, com exemplos propostos.

Módulo Compras: mostra, ao público alvo, como funciona a publicidade e aprendem quais são seus direitos e responsabilidades como consumidores. É estimulada a discussão sobre a real necessidade de comprar e as influências dos anúncios 
publicitários sobre as suas decisões.

Aplicação das palestras e a aceitação do programa pelo público: Ao final de um ano, foram realizadas mais de 226 visitas em 47 escolas, por 205 voluntários treinados, resultando mais de 450 horas de palestras atingindo mais de 6.000 alunos nas regiões da Grande São Paulo, Campinas e Rio de Janeiro.

Mensuração de resultado do programa de Educação Financeira: O programa desenvolvido originalmente na Alemanha foi motivo de estudo pela Universidade de Londres (Lührmann e Winter, 2012) e teve como objetivo a mensuração dos impactos que a iniciativa proporcionou no nível de Alfabetização Financeira dos jovens de baixa renda em escolas de ensino médio. $\mathrm{O}$ estudo teve como metodologia a aplicação de um survey em dois momentos: um questionário antes da aplicação dos treinamentos com testes para medir de forma analítica as atitudes financeiras, o comportamento e características socioeconômicas e o conhecimentosem finanças dos alunos. Todas as questões foram formuladas levando em consideração os módulos que seriam aplicados aos alunos. Após ministrar os módulos, os pesquisadoresreaplicam o questionário. Para a iniciativa brasileira, houve uma pesquisa de reação entre os estudantes participantes. Os resultados são relatados a seguir.

Expansão: A expansão do projeto foi trabalhada de forma paralela ao da sua implantação, e a cada estágio eram identificados os pontos de melhorias. O intuito é expandir os limites do programa em âmbito nacional. Entre os pontos de melhorias propostos, podemos mencionar:

Estrutura da equipe: Além da citada estrutura fixa optou-se pela formação de multiplicadores visando a sua expansão em âmbito nacional, permitindo que a expansão fosse empreendida em uma maior velocidade. Foram responsáveis pela implantação da iniciativa nas principais filiais do país da seguradora. Um dos organizadores comenta: "Os multiplicadores vêm até a sede da Seguradora e recebem todas as diretrizes do projeto, durante a implantação local, cada situação é pontuada e interagimos se necessário. "

Implantação de novos módulos: No decorrer de 2016, serão implantados os módulos "Poupança" e "Finanças na Internet". Um dos organizadores do projeto explica:

"O primeiro tem como objetivo propagar a importância em poupar recursos com vistas para o futuro, o módulo nos mostra como podemos ser mais disciplinados financeiramente. Já o segundo tem como ideia central o uso de aplicativos em celular para controle de gastos e as práticas do e-commerce".

\section{2 ultados Auferidos.}

Em 2014, recebeu o Prêmio "LIF" - que faz menção ao lema da Revolução Francesa "Liberdade, Igualdade e Fraternidade" da Câmara de Comércio BrasilFrança na categoria de apoio a comunidades locais por promover um projeto que estimulasse a Educação, promovendo transformações em prol de melhores condições para as pessoas e sociedades.

Ao final de cada treinamento, foi realizada uma pesquisa de reação entre os jovens participantes, o projeto foi de grande aceitação, sendo avaliado como excelente por $70 \%$ dos alunos, conforme figura 3, abaixo: 


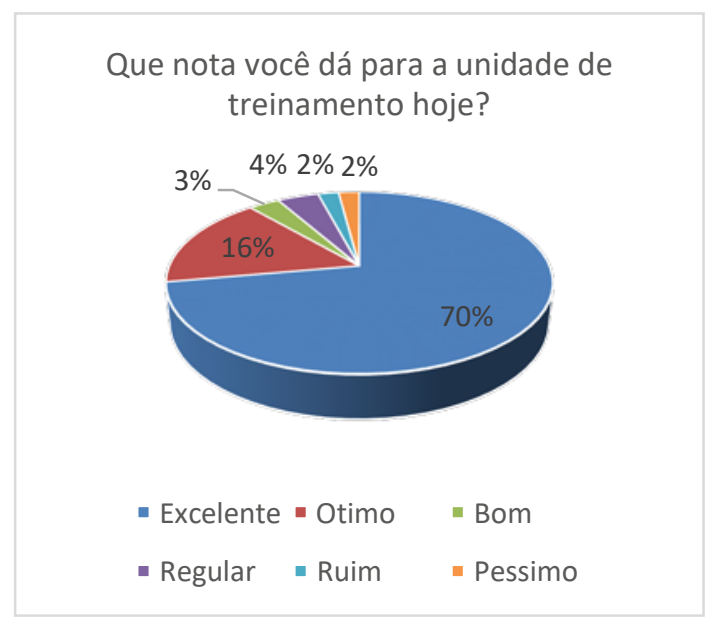

Figura 3: Fonte: Os autores. Adaptado da pesquisa de reação (2016)

Em entrevistas realizadas por uma revista voltada para o segmento de atuação da empresa, alunos relatam suas considerações sobre a iniciativa:

"Com certeza, a partir de agora, vou conseguir organizar as minhas contas e ainda asda minha família." - aluna do $3^{\circ}$ ano do Ensino Médio.

"A palestra ajuda bastante aos jovens se controlarem financeiramente. Afinal estamosentrando no mercado de trabalho agora e precisamos de uma orientação para economizar nosso dinheiro, e assim investir para o futuro. Aprendi a poupar e evitar gastos desnecessários. Foi bem bacana ter a oportunidade de participar." - aluno do $2^{\circ}$ ano do ensino médio.

"Nós somos jovens ainda, não sabemos direito o que fazer com o dinheiro. Só que a partir de agora vou fazer um planejamento para não me perder com os meus ganhos e gastos. " - aluna do $3^{\circ}$ ano do Ensino Médio. “"

\section{Conclusões e Contribuições à Prática Empresarial}

Esse estudo procurou relatar as práticas bem-sucedidas de implantação de um projeto social de Educação Financeira, descrevendo sobre suas etapas e processos. Apesar dos reveses encontrados, os resultados auferidos confirmam que o projeto obteve sucesso na sua implantação, e que está em fase de ampliação visando cobrir todas as regiões em que a Seguradora atua.

O quadro abaixo resume em cada etapa, quais foram os reveses encontrados, e quais são as experiências benéficas que os mesmos trouxeram:

\begin{tabular}{|l|l|l|}
\hline Fase de Implantação & Desafios Encontrados & Benefícios auferidos \\
\hline Estrutura Adotada & $\begin{array}{l}\text { As responsabilidades de implantação do } \\
\text { programa seriam inicialmente divididas } \\
\text { entres as várias áreas da Seguradora, } \\
\text { porém optou-se pela alocação de dois } \\
\text { funcionários em full time. }\end{array}$ & $\begin{array}{l}\text { A alocação dos funcionários em tempo } \\
\text { integral garantiu a consistência necessária } \\
\text { para a implantação do programa. }\end{array}$ \\
\hline
\end{tabular}




\begin{tabular}{|c|c|c|}
\hline Parcerias com Escolas & $\begin{array}{l}\text { Devido a experiências insatisfatórias } \\
\text { com outros projetos sociais, houve a } \\
\text { resistência por parte das escolas em } \\
\text { participar do programa. }\end{array}$ & $\begin{array}{l}\text { Após reuniões com coordenação } \\
\text { pedagógicas das escolas, o programa foi } \\
\text { implantado e as experiências bem sucedidas } \\
\text { foram utilizadas como exemplo para a } \\
\text { ampliação. }\end{array}$ \\
\hline $\begin{array}{l}\text { Voluntariado dos } \\
\text { colaboradores }\end{array}$ & $\begin{array}{l}\text { Os índices de participação em } \\
\text { programas de voluntariado são } \\
\text { historicamente baixos. }\end{array}$ & $\begin{array}{l}\text { Com campanhas internas, e outros } \\
\text { facilitadores como praticar o voluntariado } \\
\text { em expediente comercial, houve grande } \\
\text { adesão dos colaboradores. }\end{array}$ \\
\hline $\begin{array}{l}\text { Adequação dos } \\
\text { materiais didáticos }\end{array}$ & $\begin{array}{l}\text { Para não se perder a essência do } \\
\text { programa, optou-se na adoção dos } \\
\text { materiais desenvolvidos para o } \\
\text { programa alemão. }\end{array}$ & $\begin{array}{l}\text { Houve um rigoroso processo de adaptação } \\
\text { para a realidade nacional, a "tropicalização" } \\
\text { dos materiais foi um dos fatores para a boa } \\
\text { aceitação do programa. }\end{array}$ \\
\hline $\begin{array}{l}\text { Aplicação dos módulos } \\
\text { para os estudantes }\end{array}$ & $\begin{array}{l}\text { Mesmo com os treinamentos dos } \\
\text { voluntários, houve preocupação na } \\
\text { aplicabilidade dos módulos. }\end{array}$ & $\begin{array}{l}\text { Para mitigar possíveis riscos, as primeiras } \\
\text { palestras dos voluntários eram } \\
\text { acompanhadas por um dos organizadores do } \\
\text { projeto. A medida visa trazer conforto e } \\
\text { segurança para os treinadores iniciantes. }\end{array}$ \\
\hline $\begin{array}{l}\text { Avaliação dos } \\
\text { Resultados }\end{array}$ & $\begin{array}{l}\text { Com o intuito na melhoria continua, } \\
\text { realizou-se uma pesquisa de reação. }\end{array}$ & $\begin{array}{l}\text { A pesquisa de reação confirmou a boa } \\
\text { aceitação do programa, porém necessita-se } \\
\text { uma pesquisa mais profunda para avaliar o } \\
\text { grau de elevação da educação financeira } \\
\text { entre os jovens participantes do programa. }\end{array}$ \\
\hline Expansão do Programa & $\begin{array}{l}\text { Identificar os pontos de melhoria } \\
\text { visando a expansão do programa }\end{array}$ & $\begin{array}{l}\text { Ao adotar flexibilidade na implantação do } \\
\text { programa, foi possível inserir alguns pontos } \\
\text { visando a expansão do projeto. Exemplos } \\
\text { disso foram a criação de grupos de } \\
\text { multiplicadores, a tropicalização de mais } \\
\text { dois módulos, entre outros. }\end{array}$ \\
\hline
\end{tabular}

Fonte: Os autores (2016)

Como todo projeto social, existem lacunas a ser preenchidas e limitações às suasações. A maior limitação do projeto é contar com o voluntariado para que ele seja executado em sua forma. "Se faz necessário a cada ciclo, reinventar as ações e formas de abordagens voltadas aos colaboradores para manter o nível de engajamento. Turn-Over, conciliação dos horários e problemas pessoais são os fatores que mais dificultam a regularidade do voluntário no projeto", relata um dos responsáveis do programa.

Outra lacuna a ser preenchida, é a implantação dos demais módulos disponíveis na versão internacional do programa, a perspectiva é que sejam implantados todos os demais módulos em um horizonte de dois anos. No entanto, a "tropicalização" do material leva no mínimo dois meses para cada módulo.

Como contribuição principal desse relato, procurou-se sintetizar as práticas bem sucedidas e desafios encontrados na implantação de um programa de educação financeira parajovens como parte do programa de sustentabilidade. Além de relatar a importância do tema, a implantação etapa a etapa do programa, espera-se que esse relato possa servir de inspiração para outras ações parecidas, estimulando o voluntariado entre colaboradores e despertando o interesse em contribuir para a 
formação de uma sociedade melhor.

Como limitação do presente relato técnico, elencamos a falta de mensuração de forma quantitativa a elevação do nível da educação financeira entre os jovens participantes do programa, e como sugestão para estudos futuros, replicar a pesquisa originalmente desenvolvida pelos pesquisadores alemães.

\section{Referências}

Amadeu, J.R. (2009). A Educação Financeira e sua influência nas decisões de consumo e investimento: proposta de inserção da disciplina na matriz curricular. Monografia Mestrado em Educação, Universidade do Oeste Paulista, São Paulo, SP.

Ashley, P.A., Macedo-Soares, T.D.(2001), Um modelo conceitual para a incorporação da responsabilidade social a governança das relações negócios e sociedade, ENANPAD, 2001.

Batty, M., Collins, J. Michael, \& Odders-White, E. (2015). Experimental evidence on the effects of financial education on elementary school students' knowledge, behavior, and attitudes. Journal of Consumer Affairs, 49(1), 69-96

BCB Banco Central do Brasil, (2013). Caderno de Educação Financeira: Gestão de Finanças Pessoais (Conteúdo Básico).

Bernheim, B. D., Garrett, D. M., \& Maki, D. M. (2001). Education and saving: The long-termeffects of high school financial curriculum mandates. Journal of Public Economics, 80(3), 435-465.

Bertoncello, S. L. T. \& Junior, J. C. (2007). A importância da Responsabilidade Social Corporativa como fator de diferenciação. FACOM

Brasil: DECRETO $\mathrm{N}^{\circ}$ 7.397, DE 22 DE DEZEMBRO DE 2010. http://www.planalto.gov.br/ccivil_03/_Ato2007-2010/2010/Decreto/D7397.htm

Campos, M. B. (2012). Educação Financeira na Matemática do Ensino Fundamental: uma análise da produção de significados, Retirado financeira-infantil.pdf de $\quad \underline{w w w . e d u c a c a o f i n a n c e i r a . c o m . b r / t c c / i m p o r t a n c i a-d a-e d u c a c a o-~}$

Cerbasi, G.; (2004) Casais Inteligentes Enriquecem Juntos. Editora Gente, São Paulo, SP.

Coutinho, R. B. G.; Macedo-Soares, D. V. A., \& Silva, J. R. G. (2006) Projetos sociais de empresas no Brasil: arcabouço conceitual para pesquisas empíricas e análises gerenciais. Revista de Administração Pública, v. 40, n. 5, p. 763-787.

Fernandes, A. \& Gremmelmaier, J. C. (2014). Educação Financeira e Nível do 
Endividamento, Rev. Elet. Gestão e Serviços V.5, n.2.

Garcia, B.G. (2006). Responsabilidade social das empresas. Editora Peirópolis. São Paulo,SP:

Gerhardt, T. M, Levek, A. R. H. C., Benazzi A. C. M., Arnone, J. R. F., Seguin, J. \&.(2002), A responsabilidade social e sua interface com o marketing social, Rev. FAE, (maio/ago. 2002) Curitiba, v.5, n.2, p.15-25,

Gil, A.C (2008).Métodos e técnicas de pesquisa social, 6, ed. São Paulo: Atlas,

Higuchi, A. K. \& Vieira, F. G. D., (2012). Responsabilidade social corporativa e marketing social corporativo: uma proposta de fronteira entre estes dois conceitos Acta Scientiarum. Human and Social Sciences Maringá, PR.

Holzmann, R., \& Miralles, M. (2005). The role, limits of, and alternatives to financial education in support of retirement saving in the OECD, Eastern Europe and beyond. The World Bank, EUA

Harry, M. J.; Schroeder, R. (2000)Six sigma: the breakthrough management strategy revolutionizing the world's top corporations. New York: Doubleday,.

Lamóglia, L.B. (2003). Desenvolvimento pessoal uma nova abordagem na administração do voluntariado. Centro Universitário Franciscano do Paraná - FAE Business School.

Lima, M. S., \& Detoni, D. J. (2009). Educação financeira para crianças e adolescentes. Escritopara apresentação na VII Jornada Científica da UNIVEL. CPE, Cascavel, PR.

Lins, S.L.B., Pereira, R.C.F. (2011). Comprou sem querer? Entenda o porquê!. Revista Brasileira de Gestão de Negócios, out-dez 2011, Vol. 13, p. 376-395.

Lührmann, M \& Winter, J (2012)- Teaching teenagers in finance: does it work? Ludwig- Maximilians-Universität München, Munich Discussion Paper No. 2012-24.

Mascarenhas, A. O., Zambaldi, F., Varela, C. A., (2013): Motivação em programas de voluntariado empresarial: um estudo de caso. Organizações em contexto, São Bernardo do Campo, SP

Pelicioli, A. F. (2011). A relevância da educação financeira na formação de jovens, Porto Alegre, RS.

Pereira, D.H., (et al.) (2009). A Educação Financeira Infantil Seu Impacto no Consumo Consciente. Monografia Bacharel em Administração, Faculdades Integradas Campos Sales, São Paulo, SP. 
Pires, V. (207). Finanças pessoais fundamentos e dicas. Editora Equilíbrio. Piracicaba, SP:

Portal Brasil, Retirado em Abril/2016

http://www.brasil.gov.br/educacao/2014/05/educacao-financeira-chegara-a-escolaspublicas-ate-2015

Saito, A.T. (2007). Uma contribuição ao desenvolvimento da educação em finanças pessoais no Brasil. Dissertação Mestrado em Administração, Faculdade de Economia, Administração eContabilidade, Universidade de São Paulo, São Paulo, SP.

Savoia, J. R. F., Saito, A. T., \& Santana, F. D. A. (2007). Paradigmas da educação financeira no Brasil. Revista de Administração pública, 41(6), 1121-1141

Souza, D. P., \& Horizonte, B. (2012). A importância da educação financeira infantil Retirado de: www.educacaofinanceira.com.br/tcc/importancia-da-educacaofinanceira-infantil.pdf

Scheffer; G. A. B. B., (julho/setembro 2001). Programa de voluntariado empresarial: modismo ou elemento estratégico para as organizações? Revista de Administração, São Paulo v.36, n.3, p.6-14,

Tavares, Carlos, 2013, Percepção dos estudantes sobre a Educação Financeira - Estudo de Caso: Escola Secundária Manuel Lopes, Universidade de Cabo Verde, acessado em: http://bdigital.cv.unipiaget.org:8080/jspui/handle/10964/496 